\title{
Deep amplicon sequencing of preselected isolates of Parascaris equorum in $\beta$-tubulin codons associated with benzimidazole resistance in other nematodes
}

Eva Tydén ${ }^{1 *}$, Johan Dahlberg ${ }^{2}$, Olof Karlberg ${ }^{2}$ and Johan Höglund ${ }^{1}$

\begin{abstract}
Background: The development of anthelmintic resistance (AR) to macrocyclic lactones in the equine roundworm Parascaris equorum has resulted in benzimidazoles now being the most widely used substance to control Parascaris infections. However, over-reliance on one drug class is a risk factor for the development of AR. Consequently, benzimidazole resistance is widespread in several veterinary parasites, where it is associated with single nucleotide polymorphisms (SNPS) in drug targets encoded by the $\beta$-tubulin genes. The importance of these SNPs varies between different parasitic nematodes, but it has been hypothesised that they occur, at low allele frequencies, even in unselected populations. This study investigated whether these SNPs exist in the P. equorum population and tested the hypothesis that BZ resistance can develop from pre-existing SNPs in codons 167, 198 and 200 of the $\beta$-tubulin isotype 1 and 2 genes, reported to be associated with AR in strongylids. The efficacy of the oral paste formula fenbendazole on 11 farms in Sweden was also assessed.
\end{abstract}

Methods: Two isotype-specific primer pairs were designed, one on either side of the codon 167 and one on either side of codons 198 and 200. A pool of 100000 larvae was sequenced using deep amplicon sequencing by Illumina HiSeq. Faecal egg count reduction test was used to assess the efficacy of fenbendazole.

Results: No SNPs were observed in codons 167, 198 or 200 of the $\beta$-tubulin isotype 1 or 2 genes of $P$. equorum, even though 100000 larvae were sequenced. Faecal egg count reduction testing of fenbendazole showed that this anthelmintic was still 100\% effective, meaning that the likelihood of finding high allele frequency of SNPs associated with benzimidazoles resistance in $P$. equorum was low. Unexpectedly, the allele frequencies observed in single worms were comparable to those in pooled samples.

Conclusions: We concluded that fenbendazole does not exert selection pressure on the $\beta$-tubulin genes of isotypes 1 and 2 in P. equorum. The fact that no pre-existing SNPs were found in codons 167, 198 and 200 in P. equorum also illustrates the difficulties in generalising about AR mechanisms between different taxonomic groups of nematodes.

Keywords: Parascaris equorum, Anthelmintic resistance, $\beta$-tubulin, SNP, Fenbendazole, Illumina HiSeq

\footnotetext{
* Correspondence: Eva.Tyden@slu.se

'Department of Biomedical Sciences and Veterinary Public Health, Division of Parasitology, Swedish University of Agricultural Sciences, Uppsala S-750 07, Sweden

Full list of author information is available at the end of the article
}

\section{Biomed Central}

(c) 2014 Tydén et al.; licensee BioMed Central Ltd. This is an Open Access article distributed under the terms of the Creative Commons Attribution License (http://creativecommons.org/licenses/by/4.0), which permits unrestricted use, distribution, and reproduction in any medium, provided the original work is properly credited. The Creative Commons Public Domain Dedication waiver (http://creativecommons.org/publicdomain/zero/1.0/) applies to the data made available in this article, unless otherwise stated. 


\section{Background}

Parascaris equorum is a nematode parasite of foals and yearlings with a global distribution. It has a direct life cycle and is one of the most important equine parasites because of its high prevalence and severe pathogenicity [1]. For many years, this ascarid roundworm could be controlled by strategic use of different anthelmintics, including macrocyclic lactones (ML), benzimidazoles (BZ) and tetrahydropyrimidines $(\mathrm{TH})$ [2]. However, since the ML ivermectin (IVM) was first introduced in the beginning of the 1980s many horses have been dewormed with this compound up to six times during their first year, which has resulted in the development of ML resistance in the P. equorum population [3]. Furthermore, reduced efficacy of the TH pyrantel pamoate (PYR) in ML-resistant $P$. equorum isolates has been reported in the U.S. $[4,5]$. In contrast, the BZs fenbendazole (FBZ) and oxibendazole (OBZ) are still effective and is the anthelmintic drug class currently recommended for treatment of P. equorum infection [6].

It has been shown repeatedly that overuse of any anthelmintic can lead to selection of resistance-associated alleles, as experienced for different intestinal nematode parasites of livestock and horses [1]. For BZ, it is generally accepted that certain single nucleotide mutations (SNP) induce changes in amino acids, which may lead to structural changes in the drug target [1,3]. For many nematodes of veterinary interest, in particular Haemonchus contortus of sheep, BZ resistance has been associated with SNPs in the $\beta$-tubulin isotype 1 molecule, leading to reduced binding of BZ and thereby loss of anthelmintic efficacy [7]. In $H$. contortus, three different SNPs have been reported to be responsible for BZ resistance: substitution of phenylalanine (TTC) by a tyrosine (TAC) at (1) codon 200 [8-11] or at (2) codon 167, also leading to a shift from TTC by TAC at codon 200 [12], or (3) a change in glutamate (GAA) to alanine (GCA) at codon 198 [13]. Homozygous resistance mutations at more than one locus have never been found, which suggests that single mutations in the $\beta$-tubulin gene are tolerated, whereas two or more mutations make the protein dysfunctional and are lethal for the parasite [14].

The mechanisms of AR development in nematodes essentially remain unknown, but it is understood that AR can arise in three different ways $[15,16]$. Mutations in drug targets may appear spontaneously and can then spread within the parasite populations through gene flow, for example together with trade of livestock [17]. Thus mutations occur randomly and at a rate, which depends on the reproduction rate and the population size of the organism [7]. Whether the mutations are then maintained in the population depends on balancing selection [15]. For example, pre-existing polymorphisms in the parasite population could be equally selected by unilateral drug treatment, resulting in a rapid increase in the frequency of resistant alleles. The origin of $\mathrm{BZ}$ resistance in equine nematodes is generally unknown, but the presence of a TAC mutation in codon 167 has been reported in cyathostomins, even in those from horses that have never received any anthelmintic treatment [18]. Whether this indicates that TAC polymorphism was pre-existing or occurred as a result of gene flow from another population exposed to BZ is unclear [18]. Similar data on the role of $\beta$-tubulin and the development of BZ resistance in other equine nematodes such as $P$. equorum are lacking.

There are currently no studies reporting BZ resistance in $P$. equorum, but over-reliance on one drug class (in this case BZ) is regarded as a risk factor for AR development [1]. There is only one anthelmintic (fenbendazole) currently available which is still effective against $P$. equorum in Sweden. Therefore drug rotation is not possible, leading to an increased risk of selection of BZ resistance. The first objective of the present study was thus to test the hypothesis that $\mathrm{BZ}$ resistance in $P$. equorum can develop from pre-existing SNPs in codons 167, 198 and 200. This was investigated using the Illumina HiSeq next generation sequencing (NGS) technique on a pool of 100000 eggs from both pre-selected and unselected isolates of the parasite obtained from Sweden and the U.S. The second objective was to examine the anthelmintic efficacy of oral paste formula fenbendazole (FBZ) on farms in Sweden, as currently recommended for treatment of $P$. equorum in foals (http://www.sva.se/).

\section{Methods}

For an overview of the experimental design, see Figure 1.

\section{Parasite material}

Eggs were collected in October-December from the 11 Swedish farms included in the FECRT. Most foals were about 6-8 months and had been treated with both IVM and FBZ according to the deworming recommendations issued by the Swedish Veterinary Institute. Furthermore, the U.S. isolate was obtained from a closed research horse herd maintained at the University of Kentucky without anthelmintic intervention since 1979 [18], and the parasites maintained there are therefore anthelminticnaive. The second U.S. isolate (U2) was collected during routine necropsy at the Veterinary Diagnostic Laboratory, University of Kentucky. The worms from the U.S. were preserved in ethanol (70-90\%) and sent by airmail to the laboratory at the Division of Parasitology, Swedish University of Agricultural Sciences, Uppsala. Upon arrival, all worms were stored at $-70^{\circ} \mathrm{C}$ until DNA extraction was performed. 


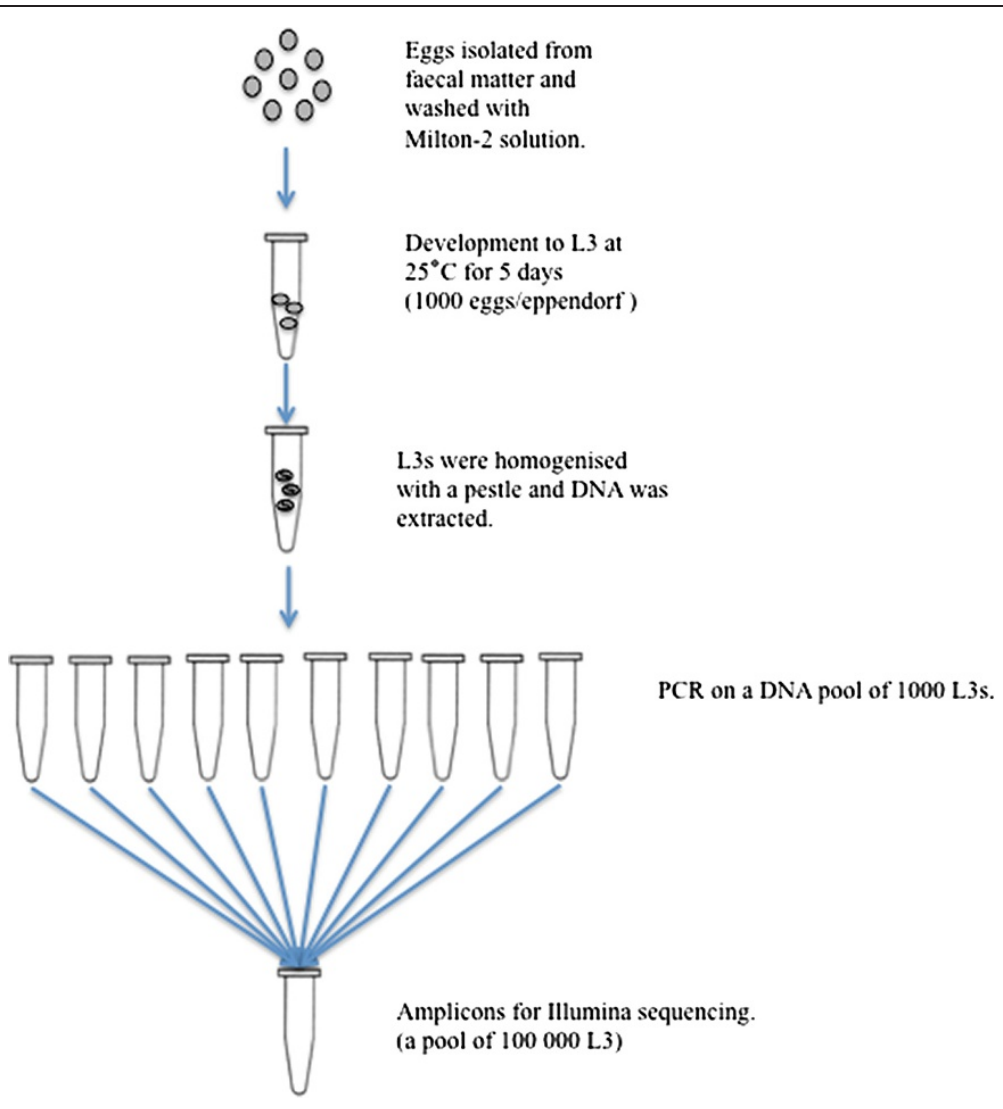

Figure 1 An overview of the experimental design for the pool of 100,000 L3.

Isolation and washing of eggs from faecal material

Parascaris eggs were isolated from foal faecal matter by sieving with different mesh sizes $(1000 \mu \mathrm{m}, 150 \mu \mathrm{m})$ and finally collected in an $80 \mu \mathrm{m}$ sieve. The eggs were further cleaned by centrifugal flotation and then diluted in tap water and stored in ventilated cell culture flasks at $7^{\circ} \mathrm{C}$.

\section{DNA extraction}

Prior to DNA extraction, the eggs were washed with Milton-2 (sodium hypochlorite 2\% (v/v) in sodium chloride 16.5\%) solution at $1500 \mathrm{rpm}$ for 3 minutes and thereafter washed with cold water several times. To increase the DNA yield, the eggs were incubated at $25^{\circ} \mathrm{C}$ for 5 days to develop into third stage larvae (L3). Eggs developed into L3 were divided into 1000 eggs/eppendorf tube and homogenised in $0.2 \mathrm{~mL}$ buffer using a plastic pestle. Complete crushing of the eggs was confirmed by light microscopy. DNA was extracted using Nucleospin Tissue (Macherey-Nagel, Düren, Germany) according to the manufacturer's instructions. The DNA extraction process described above was also performed on each individual U.S. worm. The purified DNA was stored at $4^{\circ} \mathrm{C}$ until further analysis.

\section{Primer design}

The Illumina TruSeq DNA library preparation kit used for preparation of sequencing libraries requires an amplicon size of minimum $120 \mathrm{bp}$. To achieve the right size of amplicon, the intron between the exon containing the 167 codon and the exon containing the 198 and 200 codons was cloned and sequenced using the Big Dye ${ }^{\circ}$ Terminator v3.1 Cycle Sequencing Kit Protocol (Applied Biosystems), according to the manufacturer's instructions. The sequences were determined using a Genetic Analyser (ABI PRISM ${ }^{\circ} 3100$ ). The intron sequences for $\beta$-tubulin 1 and $\beta$-tubulin 2 were edited and analysed with CLC Main Workbench version 5.6.1. A isotypespecific primer pair was designed on either side of the codon 167 and another isotype-specific primer pair on either side of codons 198 and 200 according to Figure 2.

\section{PCR}

To enable even amplification from all individuals in the pool, a touchdown PCR was carried out under the following conditions: $25 \mu \mathrm{L}$ reaction volumes containing $5 \mu \mathrm{L}$ of the DNA pool, $10 \mathrm{mM}$ Tris- $\mathrm{HCl} \mathrm{pH} 8.3,4 \mu \mathrm{g}$ Bovine Serum Albumin (BSA), $50 \mathrm{mM} \mathrm{KCl,} 2 \mathrm{mM}$ $\mathrm{MgCl}_{2}, 0.4 \mu \mathrm{M}$ of each primer, $0.24 \mathrm{mM} \mathrm{dNTP}$, and 1.5 


\begin{abstract}
Beta-tubulin isotype 1
AGATTCGTGAAGAATATCCCGACAGAATCATGAGCTCGTTCTCG GTTGTTCCATCGCCGAAGGTGCGTtcgtttttggatttgagaggaaccgaacagttcca tcacgcgacctcagctagtttaagtgagactggcgeccattctcacatttaaatcctgttttgagagtaagaa gttgcgttccgtcgaccgtggtctgcattgtttgcaggttttccgagttcttaatgctttgagtcgttcacttgcaa ggggaggatgggcagctgagtccaagtccacagtttgttatacttttgcttatgatgacttcaggaggtatcgt gcattgcattttcagGTTTCTGATGTTGTGTTGGAGCCTTACAACGCAAC GTTGTCCGTCCATCAGTTGGTTGAGAATACCGACGAGACCTTCT GCATTGACAATGAGGCTTTGTACGACATCTGCTTCAGGACTCTGA AGCTTACAAATCCCA
\end{abstract}

\section{Beta-tubulin isotype 2 AGATTCGTGAGGAGTATCCAGACCGTATTATGAGCTCGTTCTCG GTCGTCCCGTCTCCAAAGGTgagttgggtgttgcacttttttccatacgtggttcaagacc gagtttccgtcatagttgaaatgaaagtactgcaagcggatcctataaaccttctgttatattagcaacgtca aggtttctgtcacctggtttcactaaaaatgagcaccgttacccgatttcattcgttcggttactaaataggata gactttaccttgettctttattatcagaacgaaataaccaatcaggtgcggcagtaaactgagatgatctgcaa caatacttcatcattcttaactaatatgagcccagagccaagatggccaagtagtgttctgtggagtgcagat ttcgtatcatttttgcttctttatataaagtgcgagagggtttctcattcgtagGTTTCCGATGTGGT GCTGGAGCCTTACAATGCAACATTGTCTATGCATCAGCTGGTTG AGAATACGGACGAGACATTTTGCATCGATAACGAGGCGTTATAC GATATCTGCCTGAGAACGCTGAAGTTGTCTAATCCAG}

Figure 2 Position of the primers, indicated by arrows and bold font. The codons 167, 198 and 200 are marked in red. Capital letters indicate the exons and lowercase letters indicate the sequenced intron between the two exons.

U AmpliTaq GOLD DNA polymerase. All reagents were from Applied Biosystems apart from BSA, which was supplied by New England Biolabs. The touchdown cycling parameters for the amplification consisted of an initial denaturation at $95^{\circ} \mathrm{C}$ for $5 \mathrm{~min}$, followed by 10 cycles of $95^{\circ} \mathrm{C}$ for $30 \mathrm{sec}$, primer annealing at $60-50^{\circ} \mathrm{C}$ for $30 \mathrm{sec}$ with an decrease of $1^{\circ} \mathrm{C} /$ cycle, and extension at $72^{\circ} \mathrm{C}$ for $1 \mathrm{~min}$, followed by another 20 cycles for $95^{\circ} \mathrm{C}$ for $30 \mathrm{sec}$, primer annealing at $50^{\circ} \mathrm{C}$ and extension at $72^{\circ} \mathrm{C}$ for $1 \mathrm{~min}$, with a prolongation of the final extension of 5 min (Bio-Rad, My Cycler ${ }^{\mathrm{TM}}$ thermal cycler). After PCR, amplicons (a pool of 1000) were analysed by electrophoresis on Tris-Borate electrophoresis buffer (TBE) $1.5 \%$ agarose gels. Negative water controls were included in all runs. Later, the amplicons were pooled to contain 100,000 individuals and thereafter purified using Qiaquick (Qiagen). PCR amplification of the pool of 30 adult worms was performed as described above. As a check of the methodology, PCR amplification for one individual adult worm was run in parallel. Prior to Illumina sequencing, the 100,000 samples were quantified on Victor (Wallac 1420 VICTOR $_{\mathrm{TM}}^{2}$, software version 2.0) using PicoGreen ds DNA quantification kit (Molecular Probes) and diluted to $14 \mathrm{ng} / \mu \mathrm{L}$ in a total volume of $50 \mu \mathrm{L}$.

\section{Amplicon library preparation for Illumina}

Illumina HiSeq compatible sequencing libraries were prepared using the TruSeq DNA Sample Preparation Kit v2 (Illumina) according to the manufacturer's instructions, with the exception that the PCR products were used directly without a fragmentation step and no size selection was done before library amplification. The sequencing libraries were constructed with individual barcodes and all libraries were pooled and sequenced in a single lane on an Illumina HiSeq2000.

\section{Data analysis}

Each amplicon was sequenced to a minimum of 480 Mbp over Q30, yielding a coverage of at least of one million $\mathrm{X}$ per amplicon. The raw reads were aligned to their corresponding amplicon using bwa 0.6.2 (bwa aln with -q5 and bwa sampe with standard parameters) [19]. A custom tool to extract the codons of interest from each read was developed on top of the GATK Framework [20]. It was required that every base in the codon should be of Q30 quality or higher, otherwise the whole read was excluded from the analysis. Codon frequency was then determined as the fraction of the codon compared with the total number of codons observed.

\section{Faecal egg count reduction test}

A total of 110 foals, 10 foals/farm, bred and housed on 11 large stud farms in Sweden, were included in the faecal count reduction test (FECRT). The study took place in autumn 2011, after weaning. The mean age of the foals was 6.5 months, and they had been dewormed 2 or 3 times during the summer prior to the study. In the 
test, the foals were treated with FBZ as an oral paste at the standard dose rate of $7.5 \mathrm{mg} / \mathrm{kg}$ body weight (Axilur vet., Intervet Boxmeer, Netherlands). The weight of the foals was estimated visually by an experienced horse manager and rounded up to the nearest $50 \mathrm{~kg}$. Faecal samples were collected from each foal on the day of treatment (day 0) and again 14 days posttreatment (day 14), placed in plastic bags and sent to the laboratory at the Division of Parasitology, Swedish University of Agricultural Sciences, Uppsala. Samples were stored overnight at $8^{\circ} \mathrm{C}$ before analysis. The number of ascarid eggs per gram faeces (EPG) was determined both before and after treatment by a modified McMaster technique, using saturated salt as the flotation medium (specific gravity 1.2) and with lowest detection level 50 EPG [21]. Calculations of the efficacy of the FBZ were performed with the FECRT according to the formula: 1-(mean $\mathrm{EPG}_{\text {day } 0} /$ mean $\left.E P G_{\text {day } 14}\right) \times 100 \%$. Reductions were calculated using the arithmetic mean for each farm. Since there is no internationally agreed standard for evaluating the FECRT for $P$. equorum, an isolate was considered resistant when the observed reduction was $\leq 90 \%$ and the lower confidence limit was $\leq 90 \%$, and if only one criterion was met AR was suspected. This is in accordance with thresholds used for other equine nematode parasites and suggestions by [1].

\section{Results}

$\beta$-tubulin allele frequencies in codons 167, 198 and 200

The allele frequencies in a Parascaris L3 larval pool, a U.S. pool and individual worms were compared. No SNPs associated with BZ resistance were observed in codons 167,198 or 200 in the genes of $\beta$-tubulin isotype 1 (Table 1 ) or isotype 2 (Table 2 ). A similar low allele frequency as reported in the L3 larval pool and the U.S. pool was also observed in the individual worms analysed here (Additional file 1: Table S1). As such a low variation should not be present in individual worms it was most likely the result of contextdependent PCR artefacts.

A consistent difference was observed in the genetic code of codon 200 between isotypes 1 and 2, with isotype 1 having TTC and isotype 2 having TTT. This

Table 1 Allele frequency (\%) in codons 167, 198 and 200 of isotype 1

\begin{tabular}{lccc}
\hline & \multicolumn{3}{c}{ Isotype 1 } \\
\cline { 2 - 4 } & $\begin{array}{c}\text { Codon } \\
\text { 167/TTC }\end{array}$ & $\begin{array}{c}\text { Codon } \\
\text { 198/GAG }\end{array}$ & $\begin{array}{c}\text { Codon } \\
\text { 200/TTC }\end{array}$ \\
\hline Individual worm & 98.2 & 96.3 & 96.1 \\
L3 pool & 98.2 & 96.0 & 95.8 \\
U.S. pool & 98.2 & 96.1 & 95.8 \\
\hline
\end{tabular}

Table 2 Allele frequency (\%) in codons 167, 198 and 200 of isotype 2

\begin{tabular}{lccc}
\hline & \multicolumn{3}{c}{ Isotype 2 } \\
\cline { 2 - 4 } & $\begin{array}{c}\text { Codon } \\
\text { 167/TTC }\end{array}$ & $\begin{array}{c}\text { Codon } \\
\text { 198/GAG }\end{array}$ & $\begin{array}{c}\text { Codon } \\
\text { 200/TTT }\end{array}$ \\
\hline Individual worm & 98.0 & 98.1 & 97.3 \\
L3 pool & 98.3 & 98.1 & 97.4 \\
U.S. pool & 98.1 & 98.1 & 97.3 \\
\hline
\end{tabular}

difference had no impact on resistance, because TTC and TTT both code for the amino acid phenylalanine.

\section{FECRT}

Mean efficacy of the oral paste formula FBZ in reducing P. equorum EPG was tested in foals on 11 stud farms in Sweden. The FECRT showed 100\% efficacy in reducing EPG on all farms (Table 3).

\section{Discussion}

With the emergence of ML resistance, FBZ (a BZ) is the recommended drug for treatment of $P$. equorum infection in foals in Sweden. The results from the FECRT of FBZ on Swedish farms showed that no eggs appeared in the faeces 14 days post-treatment and this anthelmintic was still $100 \%$ effective. There are no previous reports of $\mathrm{BZ}$ resistance in $P$. equorum, possibly because the use of $\mathrm{BZ}$ has been restricted for therapeutic applications due to the widespread BZ resistance in cyathostomins since the mid-1970s [2].

Table 3 Results of Faecal Egg Count Reduction (FECR) test evaluating the efficacy of fenbendazole paste $(7.5 \mathrm{mg} / \mathrm{kg})$ on 11 stud farms in Sweden

\begin{tabular}{|c|c|c|c|c|}
\hline $\begin{array}{l}\text { Geographical } \\
\text { location }\end{array}$ & $\begin{array}{l}\text { Group mean } \\
\text { EPG }^{*} \text { day } 0\end{array}$ & $\begin{array}{l}\text { Group mean } \\
\text { EPG day } 14\end{array}$ & $\begin{array}{c}\text { Max } \\
\text { EPG day } 0\end{array}$ & FECR $^{* * *}$ \\
\hline Boden & 3070 & 0 & 7450 & $100 \%$ \\
\hline Borlänge & 140 & 0 & 450 & $100 \%$ \\
\hline Heby & 1580 & 0 & 3250 & $100 \%$ \\
\hline Bro & 55 & 0 & 200 & $100 \%$ \\
\hline Ekerö & 950 & 0 & 2500 & $100 \%$ \\
\hline Tystberga & 100 & 0 & 550 & $100 \%$ \\
\hline Västervik & 275 & 0 & 500 & $100 \%$ \\
\hline Västervik & 950 & 0 & 1250 & $100 \%$ \\
\hline Landskrona & 250 & 0 & 550 & $100 \%$ \\
\hline Svenljunga & 1070 & 0 & 2200 & $100 \%$ \\
\hline Sjöbo & 970 & 0 & 1150 & $100 \%$ \\
\hline
\end{tabular}


However, owing to the altered conditions today with widespread ML resistance, over-reliance on BZ must be considered an important risk factor that can lead to the emergence of multiple AR in P. equorum.

Based on SNPs in codon 200 in other nematodes of veterinary interest, $\mathrm{BZ}$ resistance is likely to be a recessive trait [9]. Therefore in light of the results from the FECRT, there was little likelihood of finding high allele frequencies of SNPs associated with BZ resistance, particularly not in the unselected pool of $P$. equorum. A total of 100,000 eggs developed to L3 stage were sequenced, but no variation was observed in codons 167,198 or 200 in $\beta$-tubulin isotypes 1 or 2 . Although the origin of $\mathrm{BZ}$ resistance in nematodes is unknown, it has been hypothesised that resistant alleles already exist within the parasite population, even prior to drug selection [10]. Furthermore, in cyathostomins the presence of TAC mutation in codon 167 is reported to occur in parasites recovered from horses that have never received anthelmintic treatment [22]. Similar findings have been made for the whipworm Trichuris trichiura, with the presence of TAC mutation in codon 200 having been identified in the population of Haiti prior to albendazole (ABZ) treatment, and in an ABZnaïve $T$. trichiura isolate from humans in Kenya $[23,24]$. No such pre-existing genetic variation in codons 167, 198 or 200 was observed in the P. equorum isolates studied here. Phylogenetic analysis of currently known isotypes has shown that representatives of the Nematoda exhibit more/greater diversity among the $\beta$ tubulin genes than representatives of the Vertebrata [25]. Based on that observation, it can be stated that associations of genetic data with BZ resistance cannot be generalised from one taxonomic group to another. This statement is further supported by the results obtained in the present study. Overall, the lack of BZ-associated SNPs in the P. equorum population observed in this study, but also in the related ascarid Ascaris lumbricoides [23], Trichurus spp. [26] and several strongylids such as Trichostrongylus tenuis [27], Necator americanus, Ancylostoma duodenale and A. caninum [28], confirms the need for caution when generalising about $\mathrm{BZ}$ resistance between different nematodes.

Recent studies in $H$. contortus have revealed associations between the selection for ML resistance and the BZ-associated SNPs in the $\beta$-tubulin gene [29]. This suggests that ML resistance could appear as a result of selection for BZ resistance [29]. However, although the Parascaris pool screened for SNPs in this study was collected from several farms with documented ML resistance [30,31], there was no evidence of a similar mechanism in Parascaris. In contrast to H. contortus, it appears that ML resistance does not select for the
BZ-associated SNPs in the $\beta$-tubulin genes of $P$. equorum. This further confirms that generalisations cannot be made regarding the mechanisms for selection of resistance between different species of nematodes.

A most important finding was the difference between the nucleotides in codon 200 in isotype 1 (TTC) and isotype 2 (TTT). This codon can thus be used to distinguish isotype 1 from isotype 2 , but it has no other impact because both TTC and TTT code for the same amino acid, phenylalanine.

Next generation sequencing (NGS) is a novel technique for mass screening of SNPs in pooled samples, since it permits rapid, deep sequencing of hundreds to thousands of DNA samples. This range of analysis is essential for uncovering the full spectrum of genetic variants occurring at low allele frequencies [32]. Accordingly, NGS is envisioned to be applied in various clinical applications, where quantitative screening of SNPs is important [33]. To date, routine molecular diagnostic testing for BZ resistance in nematode parasites of veterinary importance has mainly been based on pyrosequencing $[22,34]$. NGS has multiple advantages over conventional cloning or the single genome sequencing techniques used for semi-quantification of rare genetic variants because of its faster speed and greater depth of coverage [35]. Based on the results obtained for individual worms sequenced by NGS in parallel to the pools, we were able to conclude that errors introduced by PCR artefacts were more important for the detection limit than the current sequencing accuracy. Overall, the results from this study show that deep sequencing of amplicons with NGS provides the power to detect rare alleles when screening a large sample pool.

\section{Conclusions}

Reliance on one drug class poses a threat of multiple AR developing in P. equorum, especially in light of recent findings on the genetic homogeneity of the global Parascaris population and the high gene flow within this population [36]. In the present study, a candidate drive approach was used to screen for SNPs known to confer BZ resistance. Despite the increased use of BZ for treatment of Parascaris infection, SNPs in the $\beta$ tubulin genes known to confer resistance in other nematodes were clearly absent in P. equorum. In studies seeking new potential markers for resistance, a non-candidate driven approach would be an option for determining how AR arise. New potential markers for AR could hopefully be identified for the taxonomic group Ascaridoidea by the use of genome-wide expression profiles before and after exposure of $P$. equorum to anthelmintics. 


\section{Additional files}

Additional file 1: Table S1. Allele frequency in codons 167, 198 and 200 of isotope 1 and 2

\section{Abbreviation}

ABZ: Albendazole; AR: Anthelmintic resistance; BZ: Benzimidazoles; EPG: Eggs per gram faeces; FECRT: Faecal egg count reduction testing; FBZ: Fenbendazole; ML: Macrocyclic lactones; NGS: Next generation sequencing; OBZ: Oxibendazole; SNPs: Single nucleotide polymorphisms.

\section{Competing interests}

The authors declare that they have no competing interests.

\section{Authors' contributions}

Conceived and designed the experiments: ET, JH. Performed the experiments: ET, JD, OK. Analysed the data: ET, JH, JD, OK. Contributed reagents/materials/analysis tools: ET, JD, OK. Wrote the manuscript: ET, JH, JD, OK. All authors read and approved the final version of the manuscript.

\section{Acknowledgments}

This study was supported by the Swedish-Norwegian Foundation for Equine Research. We are grateful to the owners of the stud farms for their participation in the trial and to Martin Nielsen for sending us worms from the closed research horse herd at the University of Kentucky. Sequencing was performed by the SNP\&SEQ Technology Platform, Science for Life Laboratory, Uppsala University, a national infrastructure supported by the Swedish Research Council (VR-RFI) and the Knut and Alice Wallenberg Foundation.

\section{Author details}

${ }^{1}$ Department of Biomedical Sciences and Veterinary Public Health, Division of Parasitology, Swedish University of Agricultural Sciences, Uppsala S-750 07, Sweden. ${ }^{2}$ Department of Medical Sciences, Molecular Medicine and Science for Life Laboratory, Uppsala University, Uppsala S-751 44, Sweden.

Received: 16 June 2014 Accepted: 18 August 2014

Published: 29 August 2014

\section{References}

1. Kaplan RM: Drug resistance in nematodes of veterinary importance: a status report. Trends Parasitol 2004, 20:477-481.

2. Reinemeyer CR: Anthelmintic resistance in non-strongylid parasites of horses. Vet Parasitol 2012, 185:9-15.

3. Coles GC, Jackson F, Pomroy WE, Prichard RK, Von Samson-Himmelstjerna G, Silvestre A, Taylor MA, Vercruysse J: The detection of anthelmintic resistance in nematodes of veterinary importance. Vet Parasitol 2006, 136:167-185.

4. Craig TM, Diamond PL, Ferwerda NS, Thompson JA: Evidence of ivermectin resistance by Parascaris equorum on a Texas horse farm. J Equine Vet Sci 2007, 27:67-71.

5. Lyons ET, Tolliver SC, Ionita M, Collins SS: Evaluation of parasiticidal activity of fenbendazole, ivermectin, oxibendazole, and pyrantel pamoate in horse foals with emphasis on ascarids (Parascaris equorum) in field studies on five farms in Central Kentucky in 2007. Parasitol Res 2008 , 103:287-291.

6. Reinemeyer CR: Diagnosis and control of anthelmintic-resistant Parascaris equorum. Parasit Vectors 2009, 25(2 Suppl 2):S8.

7. Beech RN, Skuce P, Bartley DJ, Martin RJ, Prichard RK, Gilleard JS: Anthelmintic resistance: markers for resistance, or susceptibility? Parasitology 2011, 138:160-174.

8. Kwa MSG, Veenstra JG, Roos MH: Benzimidazole resistance in Haemonchus contortus is correlated with a conserved mutation in beta tubulin isotype 1. Mol Biochem Parasitol 1994, 63:299-303.

9. Elard L, Comes AM, Humbert JF: Sequences of $\beta$-tubulin CDNA from benzimidazole-susceptible and -resistant strains of Teladorsagia circumcincta, a nematode parasite of small ruminants. Mol Biochem Parasitol 1996, 79:249-253.

10. Silvestre A, Humbert JF: A molecular tool for species identification and benzimidazole resistance diagnosis in larval communities of small ruminant parasites. Exp Parasitol 2000, 95:271-276.
11. Schwab AE, Boakye DA, Kyelem D, Prichard RK: Detection of benzimidazole resistance-associated mutations in the filarial nematode Wuchereria bancrofti and evidence for selection by albendazole and ivermectin combination treatment. Am J Trop Med Hyg 2005, 73:234-238.

12. Silvestre A, Cabaret J: Mutation in position 167 of isotype $1 \beta$-tubulin gene of Trichostrongylid nematodes: role in benzimidazole resistance? Mol Biochem Parasitol 2002, 120:297-300.

13. Ghisi M, Kaminsky R, Maser P: Phenotyping and genotyping of Haemonchus contortus isolates reveals a new putative candidate mutation for benzimidazole resistance in nematodes. Vet Parasitol 2007, 144:313-320

14. Hodgkinson JE, Clark HJ, Kaplan RM, Lake SL, Matthews JB: The role of polymorphisms at $\beta$ tubulin isotype 1 codons 167 and 200 in benzimidazole resistance in cyathostomins. Int J Parasitol 2008, 38:1149-1160.

15. Gilleard JS, Beech RN: Population genetics of anthelmintic resistance in parasitic nematodes. Parasitology 2007, 134:1133-1147.

16. Slivestre A, Humbert JF: Diversity of benzimidazole-resistance alleles in populations of small ruminant parasites. Int J Parasitol 2002, 32:921-928.

17. Blouin MS, Yowell CA, Courtney CH, Dame JB: Host movement and the genetic structure of populations of parasitic nematodes. Genetics 1995 141:1007-1014.

18. Lyons ET, Tolliver SC, Collins SS, Drudge JH, Granstrom DE: Transmission of some species of internal parasites in horses born in 1993, 1994, and 1995 on the same pasture on a farm in Central Kentucky. Vet Parasitol 1997, 70:225-240.

19. Li H, Durbin R: Fast and accurate short read alignment with Burrows-Wheeler Transform. Bioinformatics 2009, 25:1754-1760.

20. McKenna A, Hanna M, Banks E, Sivachenko A, Cibulskis K, Kernytsky A, Garimella K, Altshuler D, Gabriel S, Daly M, DePristo MA: The Genome Analysis Toolkit: a MapReduce framework for analyzing next-generation DNA sequencing data. Genome Res 2010, 20:1297-1303.

21. Anonymous: Manual of Veterinary Parasitological Laboratory Techniques. London: Ministry of Agriculture Fisheries and Food; 1986:24.

22. Blackhall WJ, Kuzmina T, Von Samson-Himmelstjerna G: $\beta$-Tubulin genotypes in six species of cyathostomins from anthelmintic-naive Przewalski and benzimidazole-resistant brood horses in Ukraine. Parasitol Res 2011, 109:1199-1203.

23. Diawara A, Drake LJ, Suswillo RR, Kihara J, Bundy DA, Scott ME, Halpenny C, Stothard JR, Prichard RK: Assays to detect beta-tubulin codon 200 polymorphism in Trichuris trichiura and Ascaris lumbricoides. PLoS Negl Trop Dis 2009, 3:e397.

24. Diawara A, Halpenny CM, Churcher TS, Mwandawiro C, Kihara J, Kaplan RM, Streit TG, Idaghdour Y, Scott ME, Basáñez MG, Prichard RK: Association between response to albendazole treatment and $\beta$-tubulin genotype frequencies in soil-transmitted helminths. PLoS Negl Trop Dis 2013, 30:e2247.

25. Tydén E, Engström A, Morrison DA, Höglund J: Sequencing of the $\beta$-tubulin genes in the ascarid nematodes Parascaris equorum and Ascaridia galli. Mol Biochem Parasitol 2013, 190:38-43.

26. Hansen TVA, Nejsum P, Olsen A, Thamsborg SM: Genetic variation in codons 167, 198 and 200 of the beta-tubulin gene in whipworms (Trichuris spp.) from a range of domestic animals and wildlife. Vet Parasitol 2013, 193:141-149.

27. Webster LM, Johnson PC, Adam A, Mable BK, Keller LF: Absence of three known benzimidazole resistance mutations in Trichostrongylus tenuis, a nematode parasite of avian hosts. Vet Parasitol 2008, 158:302-310.

28. Schwenkenbecher JM, Albonico M, Bickle Q, Kaplan RM: Characterization of beta-tubulin genes in hookworms and investigation of resistanceassociated mutations using real-time PCR. Mol Biochem Parasitol 2007, 156:167-174.

29. De Lourdes MM, Prichard RK: Genetic analysis of relationship between macrocyclic lactone and benzimidazole anthelmintic selection on Haemonchus contortus. Pharmacogenet Genomics 2008, 18:129-140.

30. Lindgren K, Ljungvall Ö, Nilsson O, Ljungström BL, Lindahl C, Höglund J: Parascaris equorum in foals and in their environment on a Swedish stud farm, with notes on treatment failure of ivermectin. Vet Parasitol 2008, 151:337-343.

31. Lind EO, Christensson D: Anthelmintic efficacy on Parascaris equorum in foals on Swedish studs. Acta Vet Scand 2009, 51:45.

32. Niranjan TS, Adamczyk A, Bravo HC, Taub MA, Wheelan SJ, Irizarry R, Wang T: Effective detection of rare variants in pooled DNA samples using Cross-pool tailcurve analysis. Genome Biol 2011, 28:R93. 
33. Grossmann V, Roller A, Klein HU, Weissmann S, Kern W, Haferlach C, Dugas M, Haferlach T, Schnittger S, Kohlmann A: Robustness of amplicon deep sequencing underlines its utility in clinical applications. J Mol Diagn 2013, 15:473-484.

34. Von Samson HG, Walsh TK, Donnan AA, Carriere S, Jackson F: Molecular detection of benzimidazole resisatnce in Haemonchus contortus using real-time PCR and pyrosequencing. Parasitol 2009, 136:349-358.

35. Tsibris AM, Korber B, Arnaout R, Russ C, Lo CC, Leitner T, Gaschen B, Theiler J, Paredes R, Su Z, Hughes MD, Gulick RM, Greaves W, Coakley E, Flexner C, Nusbaum C, Kuritzkes DR: Quantitative Deep Sequencing Reveals Dynamic HIV-1 Escape and Large Population Shifts during CCR5 Antagonist Therapy In Vivo. Plos One 2009, 25:e5683.

36. Tydén E, Morrison DA, Engström A, Nielsen MK, Eydal M, Höglund J: Population genetics of Parascaris equorum based on DNA fingerprinting. $J$ Infect Genet Evol 2013, 13:236-241.

doi:10.1186/1756-3305-7-410

Cite this article as: Tydén et al.: Deep amplicon sequencing of preselected isolates of Parascaris equorum in $\beta$-tubulin codons associated with benzimidazole resistance in other nematodes. Parasites \& Vectors 2014 7:410.

\section{Submit your next manuscript to BioMed Central and take full advantage of:}

- Convenient online submission

- Thorough peer review

- No space constraints or color figure charges

- Immediate publication on acceptance

- Inclusion in PubMed, CAS, Scopus and Google Scholar

- Research which is freely available for redistribution 